\title{
Two helices in the third intracellular loop determine anoctamin 1 (TMEM16A) activation by calcium
}

\author{
Jesun Lee • Jooyoung Jung • Min Ho Tak • Jungwon Wee • Byeongjoon Lee • Yongwoo Jang • \\ Hyeyeon Chun • Dong-Jin Yang • Young Duk Yang • Sang Ho Park • Byung Woo Han • \\ Soonsil Hyun • Jaehoon Yu $\cdot$ Hawon Cho $\cdot$ H. Criss Hartzell $•$ Uhtaek Oh
}

Received: 22 July 2014 /Revised: 28 August 2014 / Accepted: 29 August 2014 / Published online: 19 September 2014

(C) The Author(s) 2014. This article is published with open access at Springerlink.com

\begin{abstract}
Anoctamin 1 (ANO1)/TMEM16A is a $\mathrm{Cl}^{-}$channel activated by intracellular $\mathrm{Ca}^{2+}$ mediating numerous physiological functions. However, little is known of the ANO1 activation mechanism by $\mathrm{Ca}^{2+}$. Here, we demonstrate that two helices, "reference" and " $\mathrm{Ca}^{2+}$ sensor" helices in the third intracellular loop face each other with opposite charges. The two helices interact directly in a $\mathrm{Ca}^{2+}$-dependent manner. Positively and negatively charged residues in the two helices are essential for $\mathrm{Ca}^{2+}$-dependent activation because neutralization of these charges change the $\mathrm{Ca}^{2+}$ sensitivity. We now
\end{abstract}

Electronic supplementary material The online version of this article (doi:10.1007/s00424-014-1603-2) contains supplementary material, which is available to authorized users.

J. Lee · J. Jung $\cdot$ M. H. Tak $\cdot$ B. Lee $\cdot$ Y. Jang $\cdot$ H. Chun $\cdot$ H. Cho $\cdot$ U. Oh $(\bowtie)$

Sensory Research Center, Creative Research Initiatives, College of Pharmacy, Seoul National University, Seoul, South Korea

e-mail: utoh@snu.ac.kr

J. Wee $\cdot$ D.-J. Yang $\cdot$ U. Oh

Department of Molecular Medicine and Biopharmaceutical Sciences, Graduate School of Convergence Science and Technology,

Seoul National University, Seoul, Republic of Korea

Y. D. Yang

Department of Pharmacy, College of Pharmacy, CHA University,

Gyeonggi, South Korea

S. H. Park • B. W. Han

Department of Pharmacy, College of Pharmacy,

Seoul National University, Seoul, Republic of Korea

S. Hyun · J. Yu

Department of Chemistry \& Education, Seoul National University,

Seoul, Republic of Korea

H. C. Hartzell

Department of Cell Biology, Emory University School of Medicine, Atlanta, GA, USA predict that the $\mathrm{Ca}^{2+}$ sensor helix attaches to the reference helix in the resting state, and as intracellular $\mathrm{Ca}^{2+}$ rises, $\mathrm{Ca}^{2+}$ acts on the sensor helix, which repels it from the reference helix. This $\mathrm{Ca}^{2+}$-dependent push-pull conformational change would be a key electromechanical movement for gating the ANO1 channel. Because chemical activation of ANO1 is viewed as an alternative means of rescuing cystic fibrosis, understanding its gating mechanism would be useful in developing novel treatments for cystic fibrosis.

Keywords Anoctamin $1 \cdot$ Anoctamin $2 \cdot$ Calcium $\cdot$ Activation $\cdot$ Helix $\cdot$ Structure

\section{Introduction}

$\mathrm{Ca}^{2+}$-activated $\mathrm{Cl}^{-}$channels $(\mathrm{CaCCs})$ mediate trans-epithelial fluid movements and thereby enable secretions in salivary glands, pancreas, intestines, and airways $[12,8,6]$; regulate vascular smooth muscle tone and cardiac myocyte excitability [50, 23, 24]; modulate neuronal cell excitability; and amplify sensory signals in retinal or olfactory sensory neurons $[8,20$, 18]. Because of this ability to regulate epithelial secretion, chemical activation of $\mathrm{CaCCs}$ is viewed as an alternative means of rescuing disabled fluid movement in the epithelia of cystic fibrosis patients [26, 25, 42].

Anoctamin 1 (ANO1; also known as TMEM16A) is a candidate for $\mathrm{Ca}^{2+}$-activated chloride channels and has biophysical and pharmacological properties similar to those of identified $\mathrm{CaCCs}[47,3,31]$. As expected for a $\mathrm{CaCC}$ candidate gene, ANO1 is expressed in the salivary gland for salivation $[47,30]$, in the airway epithelium for controlling mucin secretion [13], in the blood vessels for vascular tone [19], and in the pacemaker cells for gastrointestinal smooth muscle contraction [15]. Additionally, ANO1 is known as a heat sensor that mediates thermal pain in sensory neurons [5]. 
ANO2 is expressed in olfactory sensory neurons, suggesting its role in olfactory signal amplification $[2,35]$. ANO2 is also expressed in the hippocampus and controls synaptic excitability [14]. ANO5 is linked to a rare skeletal syndrome, gnathodiaphyseal dysplasia [21, 41, 40]. ANO6 is also known to be a $\mathrm{Ca}^{2+}$-activated $\mathrm{Cl}^{-}$channel associated with scramblase activity essential for blood clotting. Its channelopathy is associated with Scott syndrome, a rare disease of hemorrhage [46, $36,37,33,11]$.

Among the 10 isoforms of anoctamin channel family, ANO1 and ANO2 are activated by physiological concentrations of $\mathrm{Ca}^{2+}$ at the resting membrane potential $[47,29]$. Despite these multifunctional roles of the anoctamin channel family, the $\mathrm{Ca}^{2+}$ activation mechanisms remain elusive. Recently, a putative $\mathrm{Ca}^{2+}$-acting site was suggested [48]. Yu and colleagues proposed a revised topology of ANO1 using fluorescent tags at different key positions that differs from the conventional topology of ANO1 [48]. Furthermore, two Glu residues (702-EYME-705) in the third intracellular loop were suggested to be essential for the $\mathrm{Ca}^{2+}$ activation. This has been further confirmed by Scudieri and colleagues that a chimera of ANO1 replacing the third intracellular loop with that of ANO2 lowers the $\mathrm{Ca}^{2+}$ sensitivity [32]. Although these reports suggest that a region in the third intracellular loop is important for the ANO1 or ANO2 activation by $\mathrm{Ca}^{2+}$, molecular insights for the activation is largely unknown. Thus, this study pursues to determine how $\mathrm{Ca}^{2+}$ activates ANO1.

\section{Results}

The third intracellular loop is essential for $\mathrm{Ca}^{2+}$-induced ANO1 activation

In order to find potential $\mathrm{Ca}^{2+}$-binding sites in the ANO1 sequence, we first measured the $\mathrm{Ca}^{2+}$ sensitivities of ANO1 and ANO2. To this end, different concentrations of free $\mathrm{Ca}^{2+}$ were applied to the bath of inside-out membrane patches excised from human embryonic kidney (HEK) 293T cells that were transfected with Ano1 and Ano2 tagged on the Cterminus with enhanced green fluorescence protein (EGFP). Among splice variants of ANO1, we used an $\boldsymbol{a}, \boldsymbol{c}$-splice variant that has 116 residues in the $\mathrm{N}$-terminus and the 448-EAVK451 insert [9].

At $+80 \mathrm{mV}$ holding potential $\left(E_{\mathrm{h}}\right)$, the application of $\mathrm{Ca}^{2+}$ activated $\mathrm{ANO} 1$ with a half-maximal concentration $\left(\mathrm{EC}_{50}\right)$ of $0.7 \mu \mathrm{M}(n=11)$ (Fig. 1b, c). ANO2 was activated by $\mathrm{Ca}^{2+}$ with $\mathrm{EC}_{50}$ of $9.8 \mu \mathrm{M}(n=13)$. ANO1 and $\mathrm{ANO} 2$ are less sensitive to $\mathrm{Ca}^{2+}$ at $-80 \mathrm{mV}$, with respective $\mathrm{EC}_{50}$ values of $2.4(n=10)$ and $17.9 \mu \mathrm{M}(n=10)$. Because many mutants of ANO1 and ANO2 failed to respond to $\mathrm{Ca}^{2+}$ at $-80 \mathrm{mV}$, thus subsequent experiments were performed with $E_{\mathrm{h}}$ of $+80 \mathrm{mV}$. In EGFPtransfected cells, small background currents $<20 \mathrm{pA}$ were activated by maximal concentration of $\mathrm{Ca}^{2+}(100 \mu \mathrm{M} \sim$ $10 \mathrm{mM}$ ) (Fig. 1b).

Then, a mutagenesis study was performed to determine a potential $\mathrm{Ca}^{2+}$ activation site. ANO1 contains three putative sites that have multiple acidic amino acids. The first site is the Gluand Asp-rich (E/D rich) region spanning aa121 147 in the Nterminus. A deletion mutant (aa121 148) in the $\mathrm{E} / \mathrm{D}$ rich region was not expressed in the membrane and no currents were observed at a maximal $\mathrm{Ca}^{2+}$. However, a mutant having nine Asp or Glu residues replaced with Asn or Gln in the E/D rich region (120-HQNNKRFRRQQYQGNLLEAGLQLQNDQDT-148, ED9) elicited currents with $\mathrm{EC}_{50}$ value of $2.4 \mu \mathrm{M}$ comparable to wild type (Fig. 1c). The second site (285DGDYEGDNVEFND-297) in the N-terminus shares high homology with the $\mathrm{Ca}^{2+}$-binding signature sequence of the EFhand (DxDxDGxxxxxE) of calmodulin [45, 10]. Replacing all four Asp or Glu residues with Ala shifted the $\mathrm{EC}_{50}$ for $\mathrm{Ca}^{2+}$ to $17.8 \mu \mathrm{M}(n=6)$. The third potential $\mathrm{Ca}^{2+}$-binding site is located in the first intracellular loop (ICL1) between transmembrane domain 2 and 3 (TM2 and 3). This site has five consecutive Glu residues (444-EEEEEAVKDHPRAE-457), which are loosely aligned with the $\mathrm{Ca}^{2+}$-bowl region of large conductance $\mathrm{Ca}^{2+}$-activated $\mathrm{K}^{+}$channel $[1,49]$. A deletion mutant (444EEEEE-448) in this region had an $\mathrm{EC}_{50}$ of $2.1 \mu \mathrm{M}(n=8)$ [44] (Fig. 1b, c).

Recently, a revised topology of ANO1 has been proposed in which a loop that was previously thought to be extracellular forms an intracellular loop (Fig. 1a) [48]. A deletion mutant (aa 653-711) of the third intracellular loop (ICL3) in the newly proposed topology was extremely insensitive to $\mathrm{Ca}^{2+}$. The dose-response curve was shifted dramatically to the right $\left(\mathrm{EC}_{50}=2.5 \mathrm{mM}, n=10\right)$ and currents rarely showed a saturation up to $10 \mathrm{mM} \mathrm{Ca}^{2+}$ (Fig. 1c). Thus, the ICL3 region appears important for activation of ANO1 by $\mathrm{Ca}^{2+}$.

\section{Structural prediction of the ICL3 region}

In an attempt to glean insights into the structure of this region, we searched for crystal structures homologous to the ICL3 segment from the protein MODWEB server, an automated homology-modeling program (https://modbase.compbio.ucsf. edu/modweb/) that uses MODPIPE, an automated program for protein structural modeling that selects homologous structures from a large number of identified crystal structures of proteins $[7,28]$. This search revealed that a partial segment (residues 606 663) of the ICL3 of ANO2 is homologous to a part of the crystal structure (PDB ID: 3QBU) of a peptidoglycan deacetylase of Helicobacter pylori, with $31.6 \%$ sequence identity (Fig. 2a, b and Supplementary Fig. 1). The model was considered reliable because the model satisfied GA341 $(0.78$, the score based on statistical potentials higher than the pre-specified cutoff; 0.7$)$ and zDOPE $(-0.6$, an atomic distance-dependent statistical 
A

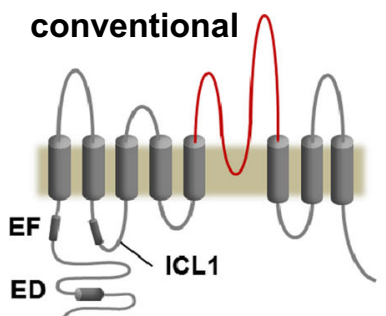

B
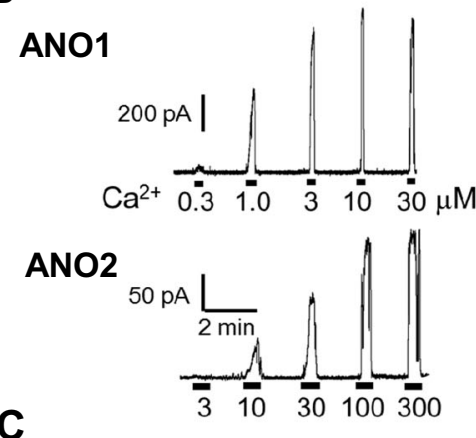

revised

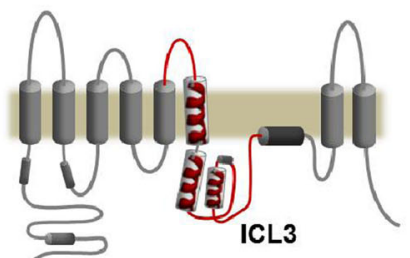

ANO1

$\Delta 5 \mathrm{E}$
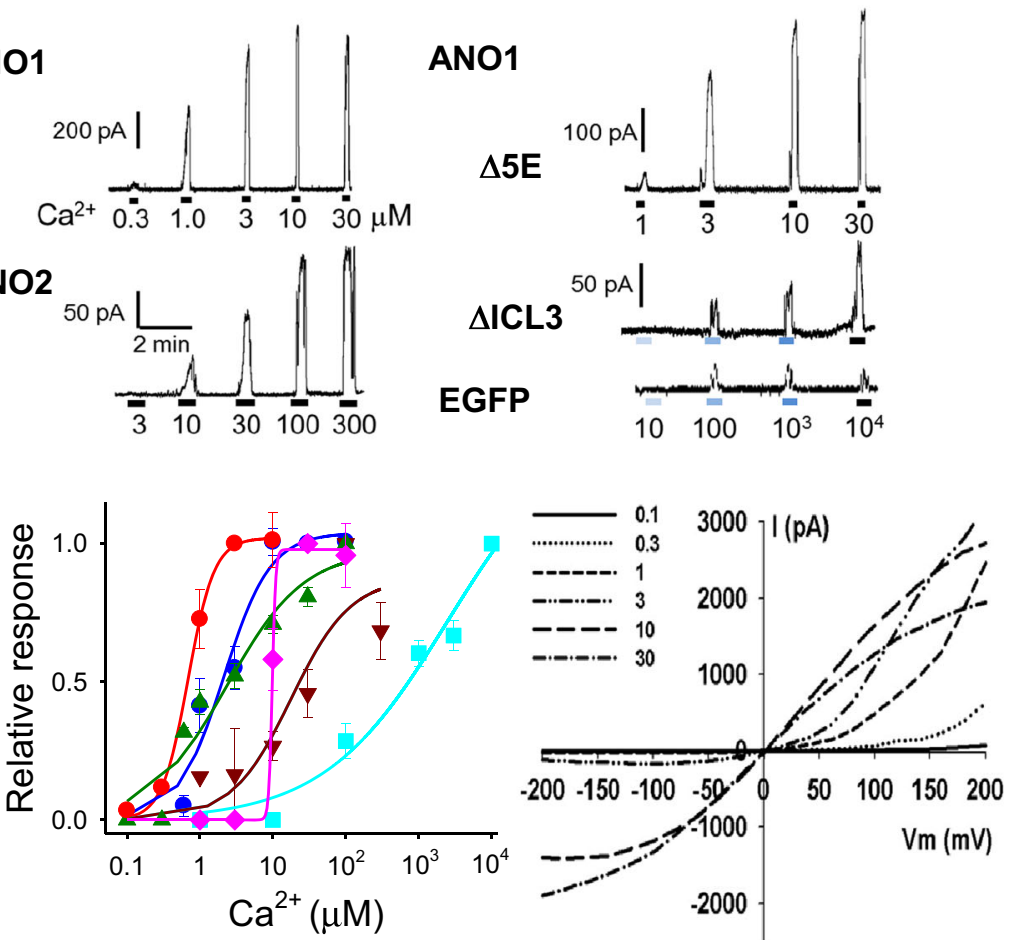

Fig. 1 ANO1 activation by $\mathrm{Ca}^{2+}$ requires the third intracellular loop (ICL3). a Proposed topologies of ANO1, conventional and revised forms. $\mathrm{ED}$, Glu, and Asp-rich region; EF EF-hand region; ICL1 and ICL3 the first and the third intracellular loops, respectively. b Example traces of channel currents of inside-out patches isolated from ANO1, ANO2, ANO1 deletion mutants, and EGFP-transfected HEK 293T cells. $\triangle 5 E$ a ANO1 deletion mutant at 444-EEEEE-448, $\triangle I C L 3$ a ANO1 deletion mutant of the third intracellular loop region. Holding potential $\left(E_{\mathrm{h}}\right)=+$ $80 \mathrm{mV}$. c Concentration-response relationships of channel currents of

potential from a sample of native structures, reliable if $\mathrm{z}$ DOPE <0) [7]. Structure-homology modeling $($ PyMOL) of the ICL3 segment of ANO2 showed two parallel $\alpha$-helices in close proximity (Fig. 2b), one of which is the Lys- and Argrich helix. Interestingly, the other helix contains the two Glu residues that had been considered important for $\mathrm{Ca}^{2+}$ sensitivity in ANO1 [48] (Fig. 2b). Because these two Glu residues appear critical for $\mathrm{Ca}^{2+}$-induced activation, we called this helix the " $\mathrm{Ca}^{2+}$ sensor helix." The counterpart helix that appears important for interacting with the $\mathrm{Ca}^{2+}$ sensor helix was called the "reference helix." The two helices were linked by 23 amino acids (Fig. 2d). We also modeled an ANO1 structure (amino acids 653-711) using the backbone of the ANO2 ICL3 region as a template. Overall, the structure of

ANO1, ANO2, and ANO1 mutants activated by various concentrations of $\mathrm{Ca}^{2+}$. Each current is normalized to the maximal response. Lines are fitted to the Hill equation, $I / I \max =1 /\left(1+\left[\mathrm{Ca}^{2+}\right] / \mathrm{EC}_{50}\right)^{n}$. $\mathrm{EC}_{50} \mathrm{~s}$ (in $\left.\mu \mathrm{M}\right)$ for ANO1 (red circle), ANO2 (pink diamond), and ANO1 mutants were $0.7(n=11), 9.8(n=13), 120$-HQNNKRFRRQQYQGNLLEAGLQLQNDQDT-148 (ED9 (green triangle), 2.4, $n=9$ ), $\Delta 5 \mathrm{E}$ (blue circle, 2.1, $n=$ 8), 285-AGAYAGA-291 (brown inverted triangle, 17.8, $n=6$ ), and $\Delta \mathrm{ICL} 3$ (light blue square, 2,509, $n=10$ ), respectively. (Right) The I/V curves of WT ANO1 at various concentration of $\mathrm{Ca}^{2+}$

ANO1 resembled that of ANO2 (Fig. 2c). When the reference helix regions were aligned, ANO1 and ANO2 had four and five basic residues, respectively.

Gating mechanism by $\mathrm{Ca}^{2+}$

Because the two parallel helices in the ICL3 region of ANO1 have amino acids with opposite charges, these opposing charges may engage in the activation of ANO1 by $\mathrm{Ca}^{2+}$. We predicted that, in the closed state, the two helices hold together primarily due to the ionic interactions between positive and negative charges in the two helices (Fig. 7f). However, as intracellular $\mathrm{Ca}^{2+}$ increases, $\mathrm{Ca}^{2+}$ binds and covers the $\mathrm{Ca}^{2+}$ sensor helix around the two Glu residues. These positive 
Fig. 2 Homology models of the ICL3 regions of ANO1 and ANO2. a A crystal structure of a part of a peptidoglycan deacetylase of Helicobacter pylori that shares structural homology with the ICL3 region of ANO2. b A homology model of the ICL3 of ANO2. Structure of the ICL3 region of ANO2 was modeled using the backbone coordinates of a deacetylase of Helicobacter pylori as a template. Side chains of Arg and Lys are shown in stick. Blue and red atoms in the side chains represent nitrogen and oxygen atoms, respectively. c A homology model of the ICL3 of ANO1. Structure of the ICL3 region of ANO1 was modeled using the backbone coordinates of the ICL3 region of $\mathrm{ANO} 2$ as a template, (right) top view. (d) Sequence alignment of the ICL3 regions of $\mathrm{ANO} 1$ and $\mathrm{ANO} 2$
A

B

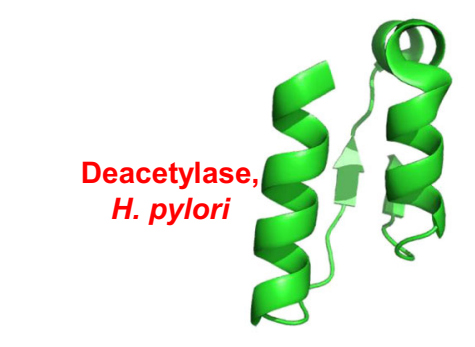

C
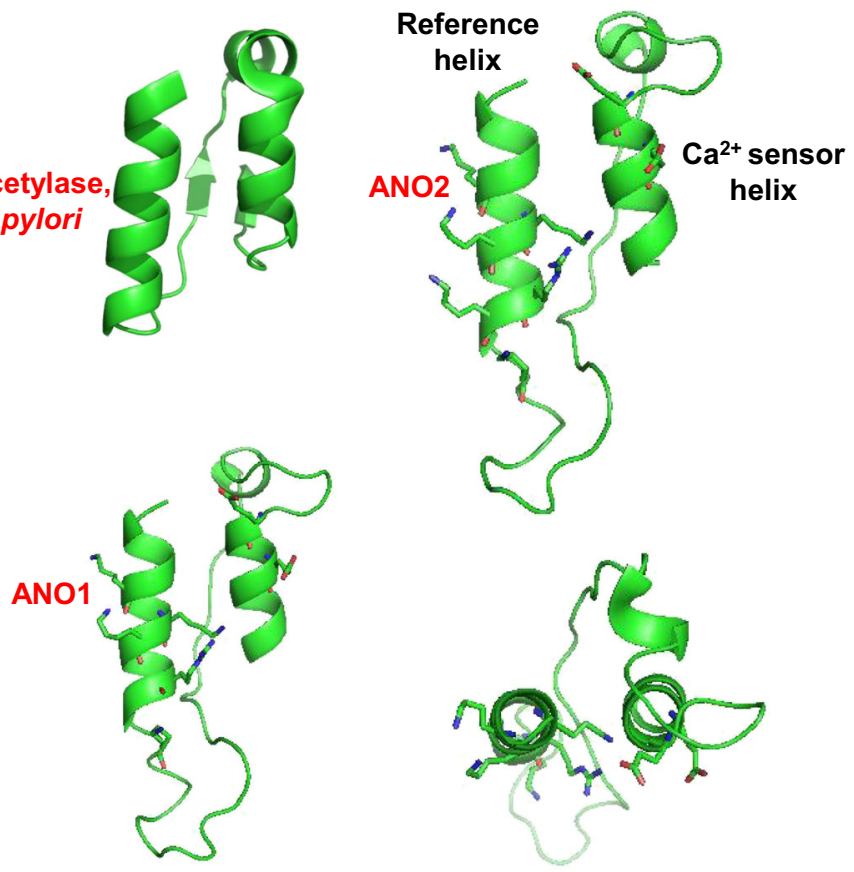

D

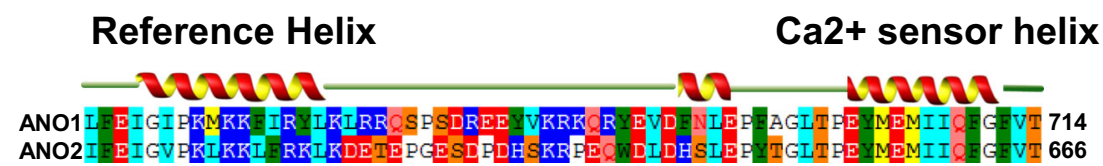

charges from the $\mathrm{Ca}^{2+}$ sensor helix may break the ionic interaction between the two helices and repel the reference helix away from the $\mathrm{Ca}^{2+}$ sensor helix (Fig. 7f). When the $\mathrm{Ca}^{2+}$ ions are removed, the $\mathrm{Ca}^{2+}$ sensor helix again moves closer to the reference helix. This conformational change of the two helices would lead to a conformational change in the channel gate.

$\mathrm{Ca}^{2+}$-dependent interaction of the reference and $\mathrm{Ca}^{2+}$-sensor helices

To confirm whether the reference helix of ANO1 forms an $\alpha$ helix, circular dichroism spectroscopy was performed with synthetic peptides spanning the reference helix regions of ANO1 (652-LFEIGIPKMKKFIRYLKL-669) and ANO2 (604-IFEIGVPKLKKLFRKLKD-621). The two peptides of ANO1 and ANO2 had a typical circular dichroism spectrum of an $\alpha$-helix with a positive band around $192 \mathrm{~nm}$ and negative bands around 208 and $222 \mathrm{~nm}$ (Fig. 3) [34].

According to the gating hypothesis, physical binding of the two helices and the interference of $\mathrm{Ca}^{2+}$ in this interaction are key determinants for gating ANO1. To investigate this relationship, physical interaction between the two helices was measured using surface plasmon resonance. A peptide segment (692-NLEPFAGLTPEYMEM-706) spanning the $\mathrm{Ca}^{2+}$ sensor helix of ANO1 was synthesized, biotinylated at the Nterminus, and immobilized on a streptavidin-coated gold sensor chip. Subsequently, a synthetic peptide spanning the

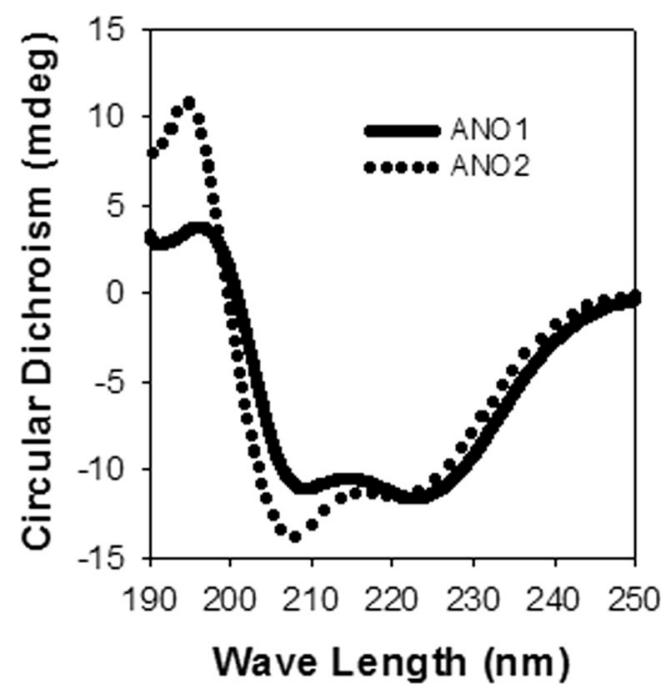

Fig. 3 Circular dichroism spectra of two reference helix peptides of $\mathrm{ANO} 1$ and $\mathrm{ANO} 2$. The two peptides that span the reference helices in the ICL 3 regions of ANO1 and ANO2 were 652LFEIGIPKMKKFIRYLKL-669 and 604-IFEIGVPKLKKLFRKLKD621 , respectively. Note a typical $\alpha$-helical character with a positive band around $192 \mathrm{~nm}$ and negative bands around 208 and $222 \mathrm{~nm}$ 
reference helix (651-NLFEIGIPKMKKFIRYLKLRR-671) was passed over the immobilized $\mathrm{Ca}^{2+}$ sensor helix. In the absence of $\mathrm{Ca}^{2+}$, the reference helix peptide interacted strongly with the $\mathrm{Ca}^{2+}$ sensor helix (Fig. $\left.4 \mathrm{a}\right)$. $\mathrm{Ca}^{2+}(0.4-2 \mathrm{mM}$ ) produced a dose-dependent reduction in the interaction between the two synthetic helix peptides. In contrast, a mutant of the reference helix peptide (651-NLFEIGIPAMAAFIAYLALAA671) in which all Lys and Arg residues were replaced with Ala failed to show any interaction with the $\mathrm{Ca}^{2+}$ sensor helix peptide regardless of $\mathrm{Ca}^{2+}$ concentration (Fig. 4b). These results clearly indicate that the two helices interact directly with each other in a $\mathrm{Ca}^{2+}$-dependent manner.

We then applied the reference helix and $\mathrm{Ca}^{2+}$ sensor helix peptides to isolated inside-out patches of HEK 293T cells transfected with ANO1, to see if the peptides antagonized $\mathrm{Ca}^{2+}$ in activating ANO1. Indeed, application of $4-\mu \mathrm{M}$

A
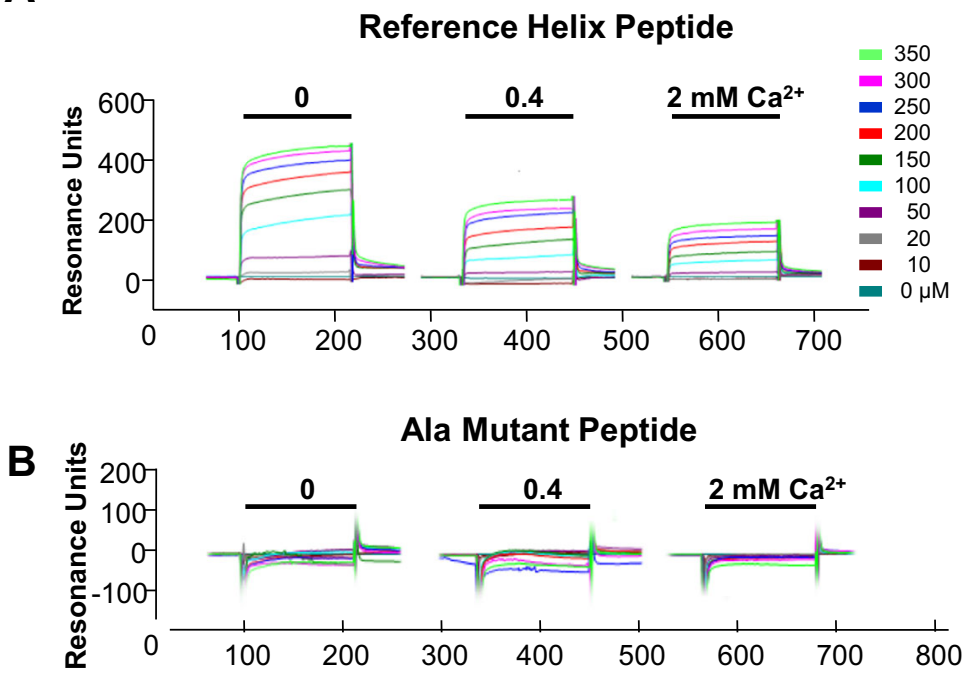

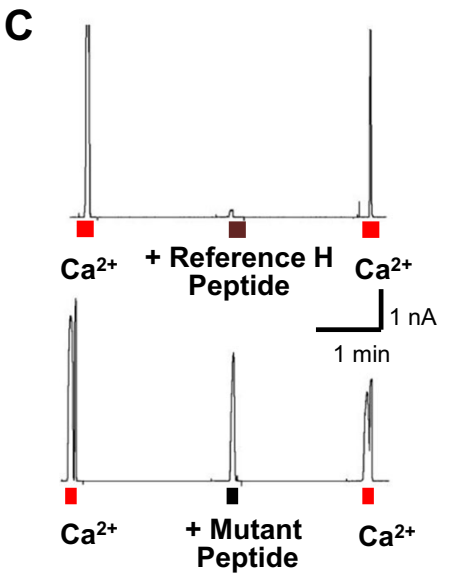

Fig. 4 The reference helix of the ICL3 region interacts with the $\mathrm{Ca}^{2+}$ sensor helix in a $\mathrm{Ca}^{2+}$-dependent way. a, b Physical interaction between the reference and $\mathrm{Ca}^{2+}$ sensor helices was assessed with a surface plasmon resonance assay. Biotinylated $\mathrm{Ca}^{2+}$ sensor helix peptide (692NLEPFAGLTPEYMEM-706) was immobilized on a streptavidin-coated gold sensor chip. Resonance intensities were measured after solutions containing $0,0.4$, and $2.0 \mathrm{mM} \mathrm{Ca}^{2+}$ and various concentrations of reference helix peptide (651-NLFEIGIPKMKKFIRYLKLRR-671) (a) or its Ala-substituted mutants (651-NLFEIGIPAMAAFIAYLALAA671) (b) were flowed through the gold chip. Note that the wild-type reference helix peptide shows a binding with the $\mathrm{Ca}^{2+}$ sensor helix in a $\mathrm{Ca}^{2+}$-dependent manner (a), which is not observed for the Alasubstituted mutant peptide (b). c $\mathrm{Ca}^{2+}$-induced ANO1 currents were blocked by bath application of the reference helix peptide (651NLFEIGIPKMKKFIRYLKLRR-671, $4 \mu \mathrm{M}$ ) to inside-out patches but
D

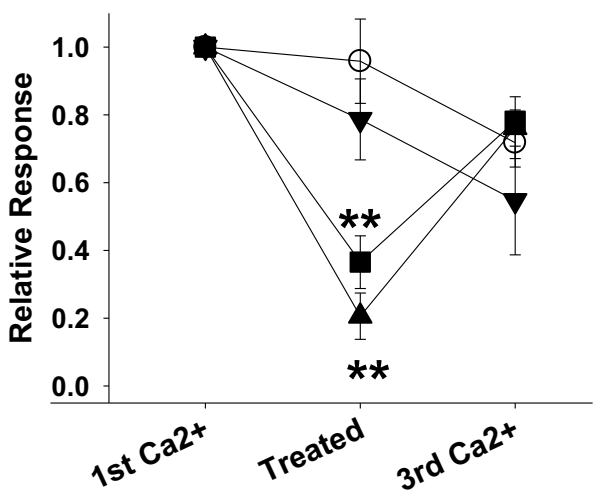

not by the Ala-mutant peptide (651-NLFEIGIPAMAAFIAYLALAA$671,4 \mu \mathrm{M})$ (lower panel). $\mathrm{Ca}^{2+}(3 \mu \mathrm{M})$ was applied three times to inside-out patches of ANO1-transfected HEK cells. At the second $\mathrm{Ca}^{2+}$ challenge, the peptides were also given. $E_{\mathrm{h}}=+80 \mathrm{mV}$. d A summary plot of the effects of applications of reference helix and $\mathrm{Ca}^{2+}$ sensor helix peptides on $\mathrm{Ca}^{2+}$-activated ANO1 currents. Current amplitudes were normalized to the current amplitude obtained after of the first $\mathrm{Ca}^{2+}$ challenge. At the second $\mathrm{Ca}^{2+}$ challenge, reference helix peptide (black circle, ${ }^{*} p<0.01$ compared to the relative response of vehicle application, one-way ANOVA, Newman-Keuls post hoc test, $n=13$ ), Alareplaced reference helix peptide (black inverted triangle, $n=8$ ), the $\mathrm{Ca}^{2+}$ sensor helix peptide (700-TPEYMEMIIQFGF-712) (black square, $* * p<0.01$ compared to the relative response of vehicle application, oneway ANOVA, Newman-Keuls post hoc test, $n=7$ ), and vehicle (white circle, $n=8$ ) were also applied 
reference helix peptide or $10-\mu \mathrm{M} \mathrm{Ca}^{2+}$ sensor helix peptide (700-TPEYMEMIIQFGF-712) markedly blocked $\mathrm{Ca}^{2+}$-induced ANO1 currents (Fig. 4c, d). In contrast, the Alamutant reference helix peptide failed to block the $\mathrm{Ca}^{2+}$-induced ANO1 currents.

Mutations in the two helices of ICL3 alter the $\mathrm{Ca}^{2+}$ sensitivity

To determine whether charged residues in the two helices are essential for the ANO1 activation by $\mathrm{Ca}^{2+}$, we constructed ANO1 and ANO2 mutants whose Arg or Lys residues in the reference helix were replaced with non-charged residues (Ala, Gln, or Gly). Replacement of single Lys residues to Gln in the upper part of the reference helix such as 659-KMKK-662 mutant caused a rightward shift of $\mathrm{EC}_{50}$ values, ranging from 3.6 to $6.1 \mu \mathrm{M}$ (Fig. 5a). When all three Lys residues in the region were replaced with Gly (659-GMGG-662), the $\mathrm{EC}_{50}$ increased to $22.8 \mu \mathrm{M}(n=6)$. Replacement of Arg or Lys residues with Gly in the lower part of the reference helix such as 665-GYLG-668 mutant shifted the $\mathrm{EC}_{50}$ value to $6.2 \mu \mathrm{M}$ $(n=6)$. Furthermore, deletion ( $\triangle$ KMKKFIRYLK) of the reference helix changed the $\mathrm{EC}_{50}$ values to $51.0 \mu \mathrm{M}(n=9)$. A mutation of the two Glu residues in the $\mathrm{Ca}^{2+}$ sensor helix (702-EYME/QYMQ-705) elicited a four-order magnitude of rightward shift in $\mathrm{EC}_{50}(11.3 \mathrm{mM}, n=7)$ (Fig. 5a). Likewise, mutations in the reference helix of ANO2 also reduced the potency of $\mathrm{Ca}^{2+}$ in opening ANO2. Replacing all three Lys residues to Gln in the upper part of the reference helix increased the $\mathrm{EC}_{50}$ from 9.8 to $50.2 \mu \mathrm{M}$. In addition, replacement to Gly of all charged residues in the reference helix (611GLGGLFGGLG-620) caused a dramatic rightward shift of

A

ANO1 ICL3

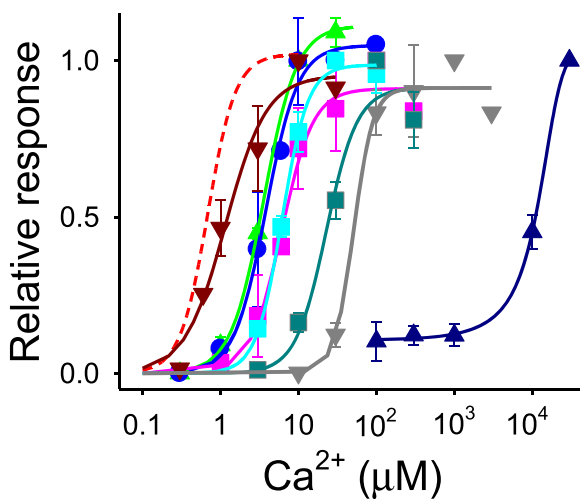

Fig. 5 Mutations in the ICL3 regions of ANO1 and ANO2 shift the sensitivity of $\mathrm{Ca}^{2+}$-dependent activation. a Replacement of Arg, Lys, or Glu residue with Ala, Gly, or Gln residue in the reference and $\mathrm{Ca}^{2+}$ sensor helices caused rightward shifts in the dose-response relationship curve of ANO1. $\mathrm{EC}_{50} \mathrm{~s}$ (in $\mu \mathrm{M}$ ) for ANO1 mutants were 659-QMKK-662 (pink square, 6.1, $n=4$ ), KMQK (blue circle, 4.7, $n=5$ ), KMKQ (green triangle, 3.6, $n=6$ ), GMGG (dark green square, 22.8, $n=6$ ), 665-GYLG668 (light blue square, $6.2, n=6$ ), deletion of 659-KMKKFIRYLK-668
$\mathrm{EC}_{50}(349 \mu \mathrm{M}, n=8)$ (Fig. 5b). Mutation of the two Glu residues in the $\mathrm{Ca}^{2+}$ sensor helix (654-EYME/AYMA-657) elicited a three-order magnitude of rightward shift in $\mathrm{EC}_{50}$ (3.3 mM, $n=6$ ) (Fig. 5b).

$E_{\text {act }}$ acts on the reference helix peptide

$E_{\text {act }}$, a synthetic agonist of ANO1, was synthesized for the purpose of treating cystic fibrosis in an attempt to bypass dysfunctioning CFTR channel [22]. Even though $\mathrm{E}_{\text {act }}$ was known to activate ANO1, the activation mechanism is not known. We therefore hypothesized that $\mathrm{E}_{\text {act }}$ also acts on the ICL3 region. Application of $1 \mu \mathrm{M} \mathrm{E}_{\text {act }}$ to the bath of insideout patch activated ANO1 (Fig. 6a). In addition, maximal $\mathrm{E}_{\text {act }}$ $(10 \mu \mathrm{M})$ activated the $\Delta 5 \mathrm{E}$ ANO1 mutant that deleted the $\mathrm{Ca}^{2+}$ bowl-like region in ICL1 (Fig. 6a). $\mathrm{E}_{\text {act }}$ also activated 285-AGAYAGA-291 mutant that replaced acidic amino acids in the EF-hand-like region in the N-terminus (data not shown). However, when applied to $\triangle \mathrm{ICL} 3$, the deletion mutant of ANO1 in the ICL3 region, $E_{\text {act }}$ failed to activate, whereas $10 \mathrm{mM} \mathrm{Ca}^{2+}$ evoked a small current (Fig. 6a). In addition, $\mathrm{E}_{\text {act }}$ failed to activate both the QYMQ (data not shown) and 659-QMQQFIAYLQ-668 mutants that neutralized charges in the $\mathrm{Ca}^{2+}$ sensor helix and reference helix, respectively (Fig. 6a). These results suggest that $\mathrm{E}_{\text {act }}$ acts on the ICL3 region.

We then applied the two helix peptides to see if these peptides compete with $\mathrm{E}_{\text {act }}$ in activating ANO1. When $10 \mu \mathrm{M} \mathrm{Ca}^{2+}$-sensor helix peptide was applied together with $1 \mu \mathrm{M} \mathrm{E}_{\mathrm{act}}$ to inside-out patches from ANO1-transfected cells, the peptide failed to inhibit $\mathrm{E}_{\text {act }}$-activated currents (Fig. 6b, c).

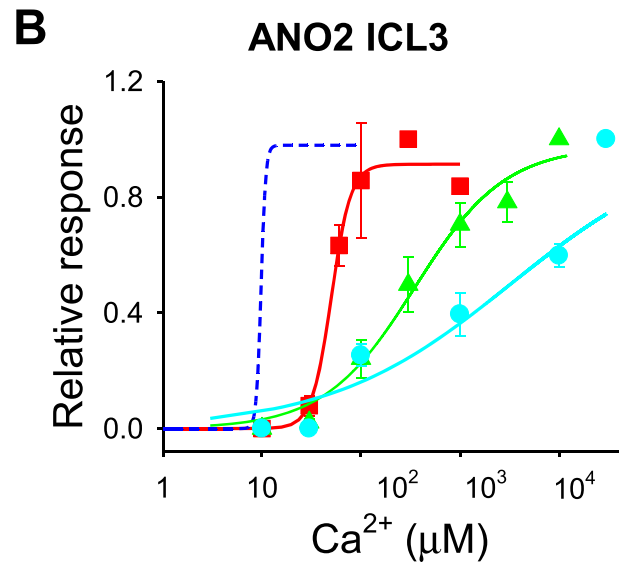

(gray inverted triangle, 51.0, $n=9$ ), 670-GGQ-672 (brown inverted triangle, 1.2, $n=7$ ), and 702-QYMQ-705 (blue square 11260, $n=7$ ). The dose-response curve of wild-type (WT) ANO1 is the same as shown in Fig. 1c (red line). b Mutations in the ICL3 region of ANO2 also shifted dose-response curves rightward. $\mathrm{EC}_{50}$ s were 611-QLQQ-614 (red square, $50.2 \mu \mathrm{M}, n=7$ ), 611-GLGGLFGGLG-620 (green triangle, $348.9 \mu \mathrm{M}$, $n=8$ ), and 654-AYMA-657 (light blue circle, $3.3 \mathrm{mM}, n=6$ ). The doseresponse curve of WT ANO2 (blue line) is same as shown in Fig. 1c 
Fig. $6 \mathrm{E}_{\text {act }}$, a synthetic agonist of ANO1 acts on the ICL3 region. a Example traces depicting activation by $\mathrm{E}_{\text {act }}$ of WT ANO1 (upper left), 444-EEEEE-448 $(\triangle 5 \mathrm{E}$, upper right), $\triangle \mathrm{ICL} 3$ (lower left), and 659-

QMQQFIAYLQ-668 mutant (lower right). b Example traces of $\mathrm{E}_{\text {act }}$-induced ANO1 currents, which were blocked by bath application of the reference helix peptide (Ref helix peptide, 651-

NLFEIGIPKMKKFIRYLKLRR$671,4 \mu \mathrm{M}$, lower panel) but not by the $\mathrm{Ca}^{2+}$ sensor helix peptide (CSH peptide, 700-

TPEYMEMIIQFGF-712, $10 \mu \mathrm{M}$, middle panel). To test the effects

of peptide, $1 \mu \mathrm{M} \mathrm{E}_{\text {act }}$ was applied three times. At the second $\mathrm{E}_{\text {act }}$ challenge, each peptide was also applied. c A summary of the effects of applications of helix peptides on $\mathrm{E}_{\text {act }}$-induced ANO1 currents. Current amplitudes were normalized to the current amplitude obtained after of the first $\mathrm{E}_{\text {act }}$ challenge. Reference helix peptide (black square, $n=5$ ), its Ala-mutant peptide (black inverted triangle, $n=5), \mathrm{Ca}^{2+}$ sensor helix peptide (black triangle, $n=5$ ), or vehicle (white circle, $n=14$ ) was applied at the second $\mathrm{E}_{\text {act }}$ challenge. ${ }^{*} p<0.05$ compared to the relative response of vehicle application, one-way ANOVA followed by NewmanKeuls post hoc test
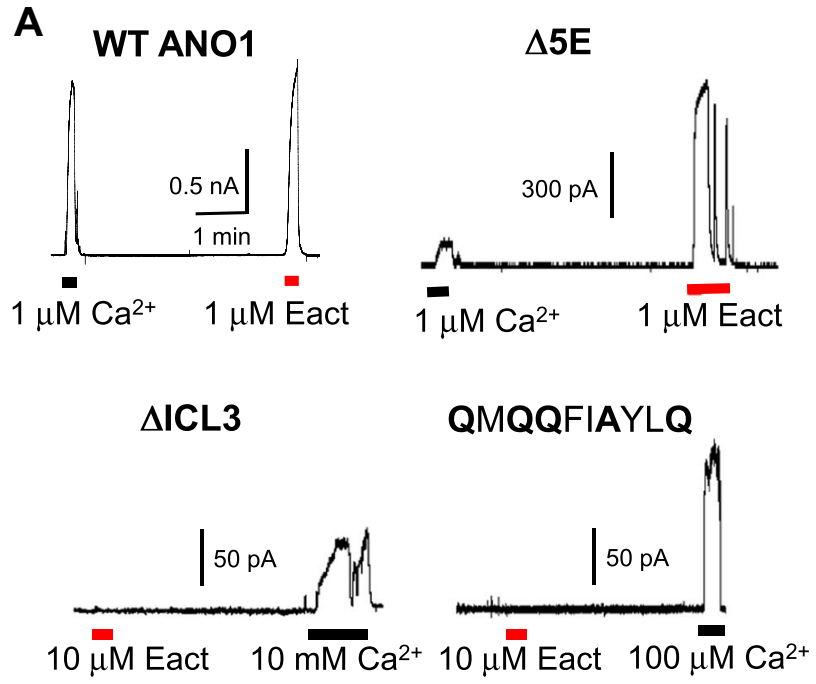

B

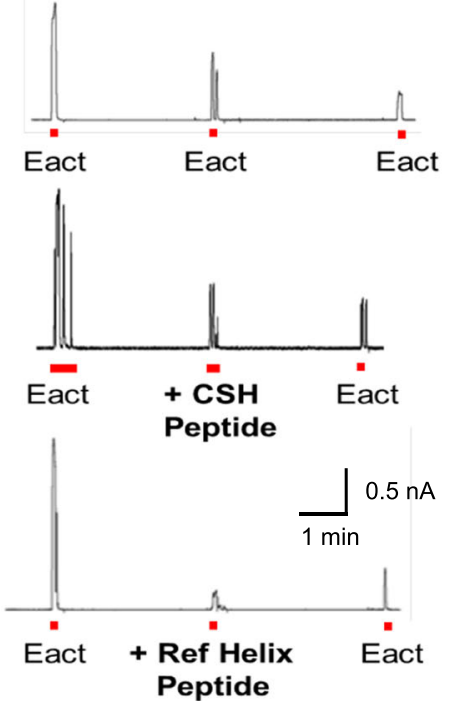

C

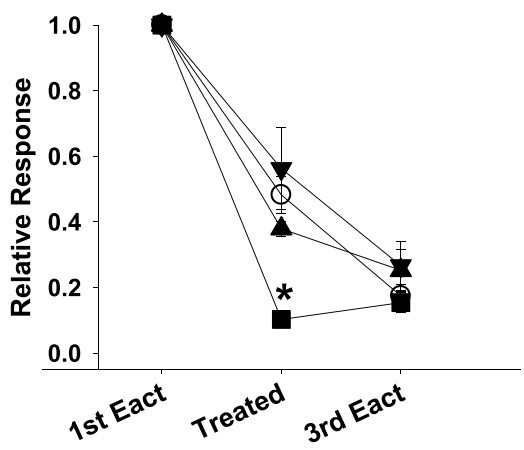

In contrast, when $4-\mu \mathrm{M}$ reference helix peptide was applied together with $E_{\text {act }}$, the peptide significantly inhibited the $E_{\text {act }}{ }^{-}$ activated ANO1 currents $(p<0.05$, one-way ANOVA, Newman-Keuls post hoc test, $n=5 \sim 14)$. However, the Alasubstituted reference helix peptide failed to inhibit the $\mathrm{E}_{\text {act }}{ }^{-}$ activated ANO1 currents (Fig. 6c). These results clearly suggest that $\mathrm{E}_{\text {act }}$ acts on the reference helix in the ICL3 region.

The two helices in the ICL3 region are dispensable for voltage- and heat-induced ANO1 activation

We reasoned that the positively charged residues in the reference helix may play a role in mediating voltage-dependent activation. Progressive replacement of Lys residues in the upper part of the reference helix shifted the half-maximal activation voltages $\left(\mathrm{V}_{1 / 2}\right)$ in $\mathrm{G}-\mathrm{V}$ curves, an indication of voltage-independent activation, from -112 to $+106 \mathrm{mV}$ without changing the slopes $(z=0.24 \sim 0.39)$ of the $\mathrm{G}-\mathrm{V}$ curve (Fig. 7b). When the ICL3 region of ANO1 (residues 653
711) was deleted, the $\mathrm{V}_{1 / 2} \mathrm{~S}$ of the $\mathrm{G}-\mathrm{V}$ curves did not vary ( + $39.5 \sim+77.3 \mathrm{mV}$ ) between $10 \mu \mathrm{M}$ and $10 \mathrm{mM}\left[\mathrm{Ca}^{2+}\right]_{\mathrm{i}}$ (Fig. 7c), which contrasts to a 294-mV change in $\mathrm{V}_{1 / 2}$ of the wild-type ANO1 (Fig. 7a). In addition, the slopes of G-V curves did not vary $(z=0.32 \sim 0.46)$ upon deletion; the ICL3 region is not a site for voltage-induced activation.

Another activation stimulus for ANO1 is heat. Bath temperature greater than $44{ }^{\circ} \mathrm{C}$ is sufficient to open the ANO1 channel [5]. Because the activation by $\mathrm{Ca}^{2+}$ and heat are synergistic, we tested whether the heat-induced ANO1 activation is also mediated by the ICL3 region. To eliminate activation by $\mathrm{Ca}^{2+}$, we removed $\mathrm{Ca}^{2+}$ from the pipette solution $\left(0 \mathrm{Ca}^{2+}\right.$ with $5 \mathrm{mM}$ ethylene glycol tetraacetic acid (EGTA)) in whole-cell recording. Surprisingly, a mutant $(\triangle \mathrm{ICL} 3)$ which hardly responded to sub-millimolar $\mathrm{Ca}^{2+}$ concentration elicited currents when the temperature of bath solution was raised over $44{ }^{\circ} \mathrm{C}$ (Fig. $7 \mathrm{~d}$, e). Thus, these results suggest that the activation mechanism of ANO1 by heat is different from that by $\mathrm{Ca}^{2+}$. 
A

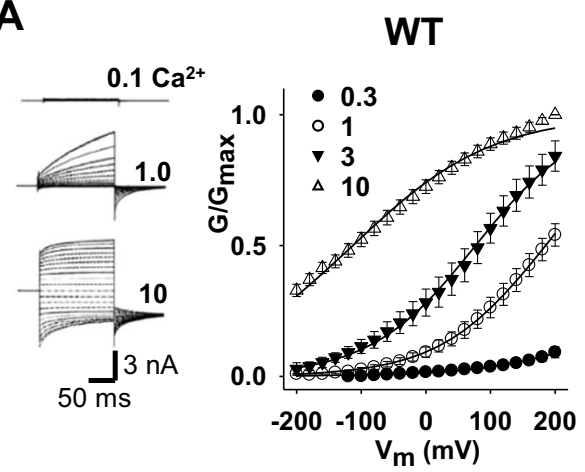

B Reference H C

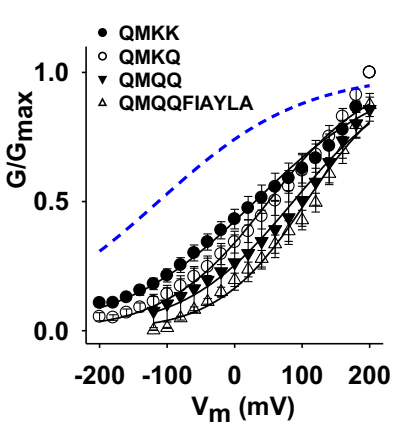

$\triangle \mathrm{ICL} 3$

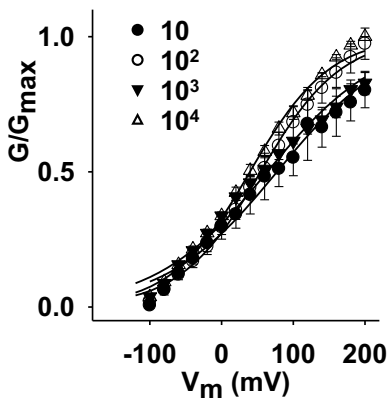

D

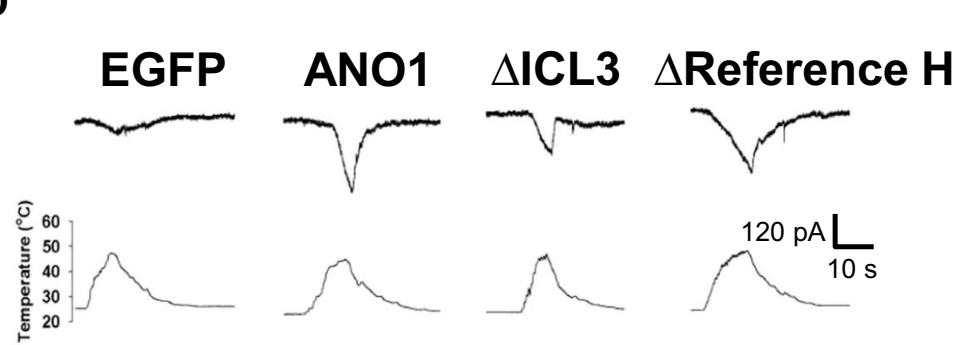

E

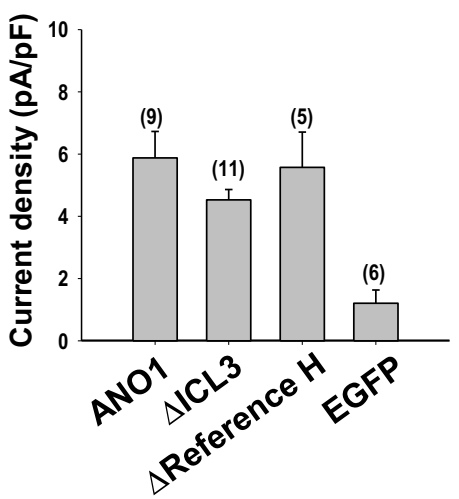

$\mathbf{F}$

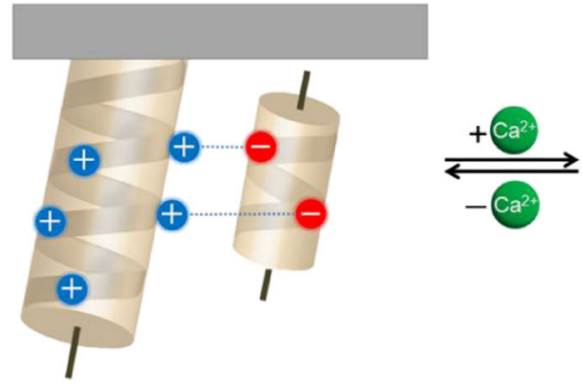

Fig. 7 The two helices in the ICL3 region are dispensable for voltageand heat-induced ANO1 activation. a Current responses of WT ANO1 to voltage pulses ( -200 to $+200 \mathrm{mV}$ in $20-\mathrm{mV}$ increment) at $0.1,1.0$, and $10 \mu \mathrm{M} \mathrm{Ca}^{2+}$ (left). A G-V curve of WT ANO1 at $0.3,1.0,3.0$, and $10 \mu \mathrm{M}$ $\mathrm{Ca}^{2+}($ right $) . \mathrm{G} / \mathrm{G}_{\max } \mathrm{s}$ at different $\left[\mathrm{Ca}^{2+}\right]_{i}$ were plotted against membrane potential $\left(V_{\mathrm{m}}\right)$. b, $\mathbf{c} \mathrm{G}-\mathrm{V}$ curves of various mutants in the reference helix at $10 \mu \mathrm{M}\left[\mathrm{Ca}^{2+}\right]_{i}$ (b) and an ICL3-deleted mutant (residues 653-711) of

\section{Discussion}

With homology modeling, we predict that the ICL3 region in the revised topology of ANO1 has a unique structure composed of two parallel helices that interact with each other in a $\mathrm{Ca}^{2+}$-dependent manner and cause rightward shifts in the $\mathrm{Ca}^{2+}$ sensitivity upon mutation. Furthermore, $\mathrm{E}_{\text {act }}$, a synthetic agonist of ANO1, also acts on the ICL3 region. However, the two helices apparently do not control voltage-induced activation because mutagenesis did not change the sensitivity to voltage. Furthermore, the ICL3 region does not account for heat-

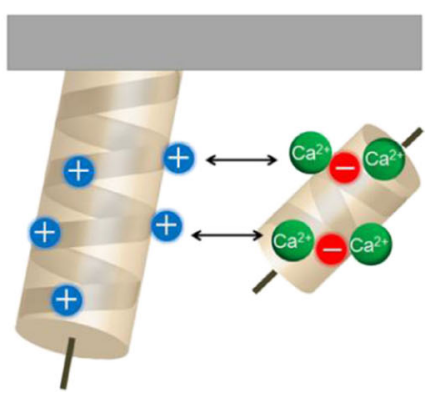

ANO1 at $10 \mu \mathrm{M} \sim 10 \mathrm{mM}\left[\mathrm{Ca}^{2+}\right]_{i}$ (c). The G-V curve of WT ANO1 was the same as shown in Fig. 7a (black line). $\mathbf{d}$ Traces of heat-induced wholecell currents of EGFP-, WT-, $\triangle$ ICL3-, and $\Delta$ reference helix mutant ( $\Delta 659-668)$-transfected HEK $293 \mathrm{~T}$ cells. $E_{\mathrm{h}}=-60 \mathrm{mV}$. e A summary of heat-induced currents of ANO1 and its mutants. f A schematic diagram depicting a molecular mechanism underlying $\mathrm{Ca}^{2+}$-dependent activation of ANO1 at the ICL3 region

induced activation. Although this study is based on homology modeling, present experimental data including surface plasmon resonance (SPR) assay, circular dichroism analysis, as well as mutational study along with electrophysiological experiments support the structure model.

According to the model of ICL3 of ANO1, several structural elements appear important for the activation by $\mathrm{Ca}^{2+}$. The two helices are oppositely charged. The role of positive charges in the reference helix appears to hold the $\mathrm{Ca}^{2+}$ sensor helix in the resting state. We imagine that the reference helix pushes the $\mathrm{Ca}^{2+}$-sensor helix away when $\mathrm{Ca}^{2+}$ ions attach to it 
(Fig. 7f). Thus, removal of these positive charges in the reference helix decreases the direct binding and sensitivity to $\mathrm{Ca}^{2+}$ concentrations. However, because the removal of positive charges in the reference helix showed two-order differences in $\mathrm{Ca}^{2+}$ sensitivity that is smaller than the four-order change with the mutant in the $\mathrm{Ca}^{2+}$ sensor helix (Fig. 5a), factors other than the ionic interaction may also contribute to the movement of two helices by $\mathrm{Ca}^{2+}$. In line with this, positively charged amine residues of Lys and Arg in the reference helix do not align along one side facing the $\mathrm{Ca}^{2+}$ sensor helix. Instead, these positive charges distribute in many directions in a circular fashion (Fig. 3). In addition, only ANO1 and ANO2 are sensitive to physiological range of $\mathrm{Ca}^{2+}$ at the resting membrane potential and have the helixloop-helix structure in the ICL3 region. It is uncertain whether other ANO family members have this structural element. It is conceivable that these other ANO channels may have different mechanisms for channel gating if they are channels. However, as ANO6 has been suggested as a scramblase [46, 36], other ANO family members may function other than channels.

Many studies tried to define the $\mathrm{Ca}^{2+}$ activation site in ANO1. Initially, the $\mathrm{Ca}^{2+}$ bowl-like region in the ICL1 was studied for the $\mathrm{Ca}^{2+}$ sensitivity [44]. However, the deletion of the region failed to show a shift in the $\mathrm{Ca}^{2+}$ sensitivity. The lack of change in the $\mathrm{Ca}^{2+}$ sensitivity of mutants in this region of ANO1 and ANO2 was also observed by others [4]. Furthermore, Tien and colleagues observed that an " $a$ " variant of ANO1 lacking the "EAVK" residues retains the $\mathrm{EC}_{50}$ of $\mathrm{Ca}^{2+}$ less than $1 \mu \mathrm{M}$, comparable to that of the " $\boldsymbol{a}, \boldsymbol{c}$ " variant [38]. Similarly, we also failed to see a discernible change in $\mathrm{EC}_{50}$ after the deletion of 444-EEEEE-448 (Fig. 1b, c). In contrast, Xiao and Cui reported that the deletion of 444EEEEEAVK-451 shifted $\sim 40$-fold increase in $\mathrm{EC}_{50}$ [43]. $\mathrm{Yu}$ and colleagues found the acidic residues, E702 and E705, in the ICL3 region of the revised topology that were critical for the $\mathrm{Ca}^{2+}$ sensitivity of ANO1 [48]. Scudieri and colleagues also confirmed that this region is sensitive to the $\mathrm{Ca}^{2+}$-dependent activation [32]. The present study also confirmed that this region is important for the ANO1 activation by $\mathrm{Ca}^{2+}$. Recently, Tien and colleagues also suggest that the ICL3 region is an important site for the $\mathrm{Ca}^{2+}$ sensitivity [38]. They extended mutation to E734 (equivalent to E730 in " $\boldsymbol{a}$ " variant) and D738 (equivalent to D734 in " $\boldsymbol{a}$ " variant) residues beyond the E702 and E705 residues and found that the E734 and D738 are involved in the $\mathrm{Ca}^{2+}$-dependent gating, because mutations in these residues made a large shift in $\mathrm{EC}_{50}$. Thus, Tien and colleagues proposed that the $\mathrm{Ca}^{2+}$ caging with the four Glu and Asp residues is essential for the ANO1 activation. It is not clear how $\mathrm{Ca}^{2+}$ binding to this site gates ANO1. It is conceivable that these additional Glu734 and Asp738 residues may affect the interaction between $\mathrm{Ca}^{2+}$ and the reference $\mathrm{Ca}^{2+}$ sensor helices, because the two Glu and Asp residues are close to the $\mathrm{Ca}^{2+}$ sensor helix. However, to identify the interactions between the two helices and the E734 and D738 residues requires further study.

In the present study, high $\mathrm{Ca}^{2+}$ evoked currents in $\triangle \mathrm{ICL} 3$ mutant-expressing HEK cells. This remnant current is probably caused by endogenous ANO isoforms present in native HEK cells. HEK cells are known to have ANO6 and 8 [27]. Thus, the current activated by high $\mathrm{Ca}^{2+}$ in $\triangle \mathrm{ICL} 3$ mutantexpressing cells would be currents of endogenous ANO6 or other isoforms in HEK cells. Another possibility is that there are multiple sites other than the ICL3 region in ANO1 that controls the $\mathrm{Ca}^{2+}$-dependent activation. So, the deletion of the ICL3 region may not remove all the currents activated by $\mathrm{Ca}^{2+}$.

In summary, this study demonstrates the structural basis of channel gating by $\mathrm{Ca}^{2+}$ and voltage in ANO1. Although electrophysiological, protein chemistry, and structure modeling have predicted that opposite charges between the two helices in the ICL3 play critical roles in channel gating, the precise mechanism underlying the activation requires crystal structure analysis. Because ANO1 and other family members mediate numerous physiologic functions, elucidation of the activation mechanism by $\mathrm{Ca}^{2+}$ is essential for a detailed understanding of ANO-related pathophysiology. ANO1 agonists are now considered to be useful in the management of cystic fibrosis. Understanding structural and molecular mechanisms for ANO1 activation is useful in designing anti-cystic fibrosis drugs.

\section{Materials and methods}

\section{Mutagenesis and gene expression}

All mutants were generated from the wild-type construct, mouse ANO1 (pEGFP-N1-mANO1). Amino acid substitution or deletion mutants were prepared using a site-directed mutagenesis kit (Muta-direct, iNtRON Biotech) or by using the overlap PCR method. Mutations in all mutants were confirmed by sequencing whole nucleotide sequences. HEK 293T cells were transfected with $1 \mu \mathrm{g}$ of pEGFP-N1-mANO1 or pEGFP-N1-mutants, $0.05 \mu \mathrm{g}$ pEGFP-N1, and FuGENE (Roche Diagnostics, Penzberg, Germany) in 35-mm dishes. Transfected cells were incubated in DMEM supplemented with $10 \%$ fetal bovine serum (GIBCO) and penicillinstreptomycin at $37{ }^{\circ} \mathrm{C}$ in a $5 \% \mathrm{CO}_{2}$ incubator. Cells were used 1 or 2 days after transfection.

\section{Electrophysiology}

Borosilicate glass pipettes (World Precision Instruments, Sarasota, FL) with tip resistances of $\sim 2$ Mohms were used to form gigaseals on HEK cells. Inside-out membrane patches were excised by pulling the pipette away from the cell. 
Currents were recorded with a patch-clamp amplifier (Axopatch 200B, Molecular Probes) with a $1-\mathrm{KHz}$ filter. Data from the amplifier were digitized with Digidata 1440A (Molecular Probes) and stored on a computer.

The control pipette solution contained $140 \mathrm{mM} \mathrm{N}$-methyl D-glucamine, $2 \mathrm{mM} \mathrm{MgCl}$, and $10 \mathrm{mM}$ HEPES adjusted to pH 7.2 with $\mathrm{HCl}$. For $\mathrm{Ca}^{2+}$-free solution, $10 \mathrm{mM}$ ethylene glycol tetraacetic acid (EGTA) was added to the control solution. The bath solution contained (in mM) $140 \mathrm{~N}$-methyl Dglucamine, $2 \mathrm{MgCl}_{2}, 10$ HEPES, 10 chelator (EGTA, N(2hydroxyethyl) ethylenediamine triacetic acid (HEDTA), or nitrilotriacetic acid (NTA)), and a calculated amount of $\mathrm{CaCl}_{2}$ (adjusted with $\mathrm{HCl}$ to $\mathrm{pH}$ 7.2). EGTA was used for $0.1 \sim 1.0 \mu \mathrm{M}$ free $\mathrm{Ca}^{2+}$, whereas HEDTA and NTA were used for 3.0 30 and 100 1,000 $\mu \mathrm{M}$ free $\mathrm{Ca}^{2+}$, respectively [39]. No chelator was added to solutions with free $\mathrm{Ca}^{2+}$ greater than $1 \mathrm{mM}$. To calculate free $\mathrm{Ca}^{2+}$ in pipette solutions, the WEBMAXC program was used (http://www.stanford.edu/ $\sim$ cpatton/webmaxc/webmaxcS.htm). Free $\mathrm{Ca}^{2+}$ less than $30 \mu \mathrm{M}$ in each solution was monitored with Fura-2 fluorometry [17].

\section{Surface plasmon resonance measurement}

A Biacore 3000 was used for kinetic surface plasmon resonance measurement as previously described [16]. Briefly, a biotinylated peptide (692-NLEPFAGLTPEYMEM-706) was immobilized on a SA chip or custom streptavidin-coated CM5 sensor chip (GE Healthcare), with one flow cell with biotin alone as a reference cell. For the binding assay, HEPESbuffered saline containing $0.005 \%$ of Tween 20 was used as a running buffer. Various concentrations of the reference helix peptide (aa 651-671) were injected for $120 \mathrm{~s}$ and dissociated for $240 \mathrm{~s}$ at a flow rate of $20 \mu \mathrm{L} / \mathrm{min}$. Binding curves were analyzed using BIAevaluation 3.1.

\section{Structure homology modeling}

The amino acid residues of third intracellular loop (residues 603-663) in ANO2 were selected as the target sequence for homology modeling. Automated homology modeling was implemented by MODWEB (http://salilab.org/modweb), a web server for automated comparative protein structure modeling.

Acknowledgements This research was supported by a grant from the National Research Foundation of Korea (no. 20110018358), a grant from BK21+ program of Ministry of Education of Korea, and NIH grants GM60448 and EY114852 (HCH)

Author contributions JL recorded channel currents and carried out structural modeling; JJ carried out the $\mathrm{Ca}^{2+}$ overlay and SPR assays; JW, BL, YJ, and YDY worked on mutagenesis; MHT, HC, DJY, and HwC carried out current recordings; SHP and BWH worked on structural modeling; SH and JY worked on SPR assay; $\mathrm{HCH}$ planned and wrote the manuscript; and OU planned, supervised experiments, and wrote the manuscript.

Conflict of interest The authors declare that they have no conflict of interest.

Open Access This article is distributed under the terms of the Creative Commons Attribution License which permits any use, distribution, and reproduction in any medium, provided the original author(s) and the source are credited.

\section{References}

1. Bian S, Favre I, Moczydlowski E (2001) Ca2+-binding activity of a $\mathrm{COOH}$-terminal fragment of the Drosophila BK channel involved in Ca2+-dependent activation. Proc Natl Acad Sci U S A 98(8): 4776-4781

2. Billig GM, Pal B, Fidzinski P, Jentsch TJ (2011) Ca2+-activated Clcurrents are dispensable for olfaction. Nat Neurosci 14(6):763-769

3. Caputo A, Caci E, Ferrera L, Pedemonte N, Barsanti C, Sondo E, Pfeffer U, Ravazzolo R, Zegarra-Moran O, Galietta LJ (2008) TMEM16A, a membrane protein associated with calcium-dependent chloride channel activity. Science 322(5901):590-594

4. Cenedese V, Betto G, Celsi F, Cherian OL, Pifferi S, Menini A (2012) The voltage dependence of the TMEM16B/anoctamin2 calcium-activated chloride channel is modified by mutations in the first putative intracellular loop. J Gen Physiol 139(4):285294

5. Cho H, Yang YD, Lee J, Lee B, Kim T, Jang Y, Back SK, Na HS, Harfe BD, Wang F, Raouf R, Wood JN, Oh U (2012) The calciumactivated chloride channel anoctamin 1 acts as a heat sensor in nociceptive neurons. Nat Neurosci 15(7):1015-1021

6. Eggermont J (2004) Calcium-activated chloride channels: (un)known, (un)loved? Proc Am Thorac Soc 1(1):22-27

7. Eswar N, John B, Mirkovic N, Fiser A, Ilyin VA, Pieper U, Stuart AC, Marti-Renom MA, Madhusudhan MS, Yerkovich B, Sali A (2003) Tools for comparative protein structure modeling and analysis. Nucleic Acids Res 31(13):3375-3380

8. Frings S, Reuter D, Kleene SJ (2000) Neuronal Ca2+-activated Clchannels - homing in on an elusive channel species. Prog Neurobiol 60(3):247-289

9. Galietta LJ (2009) The TMEM16 protein family: a new class of chloride channels? Biophys J 97(12):3047-3053

10. Gifford JL, Walsh MP, Vogel HJ (2007) Structures and metal-ionbinding properties of the Ca2+-binding helix-loop-helix EF-hand motifs. Biochem J 405(2):199-221

11. Grubb S, Poulsen KA, Juul CA, Kyed T, Klausen TK, Larsen EH, Hoffmann EK (2013) TMEM16F (anoctamin 6), an anion channel of delayed Ca2+ activation. J Gen Physiol 141(5): $585-600$

12. Hartzell C, Putzier I, Arreola J (2005) Calcium-activated chloride channels. Annu Rev Physiol 67:719-758

13. Huang F, Zhang H, Wu M, Yang H, Kudo M, Peters CJ, Woodruff PG, Solberg OD, Donne ML, Huang X, Sheppard D, Fahy JV, Wolters PJ, Hogan BL, Finkbeiner WE, Li M, Jan YN, Jan LY, Rock JR (2012) Calcium-activated chloride channel TMEM16A modulates mucin secretion and airway smooth muscle contraction. Proc Natl Acad Sci U S A 109(40):16354 
14. Huang WC, Xiao S, Huang F, Harfe BD, Jan YN, Jan LY (2012) Calcium-activated chloride channels (CaCCs) regulate action potential and synaptic response in hippocampal neurons. Neuron 74(1): 179-192

15. Hwang SJ, Blair PJ, Britton FC, O'Driscoll KE, Hennig G, Bayguinov YR, Rock JR, Harfe BD, Sanders KM, Ward SM (2009) Expression of anoctamin 1/TMEM16A by interstitial cells of Cajal is fundamental for slow wave activity in gastrointestinal muscles. J Physiol 587(Pt 20):4887-4904

16. Hyun S, Lee KH, Han A, Yu J (2011) An RNA aptamer that selectively recognizes symmetric dimethylation of arginine 8 in the histone H3 N-terminal peptide. Nucleic Acid Ther 21(3): $157-163$

17. Jung J, Nam JH, Park HW, Oh U, Yoon JH, Lee MG (2013) Dynamic modulation of ANO1/TMEM16A HCO3(-) permeability by $\mathrm{Ca} 2+/$ calmodulin. Proc Natl Acad Sci U S A 110(1):360-365

18. Lowe G, Gold GH (1993) Nonlinear amplification by calciumdependent chloride channels in olfactory receptor cells. Nature 366(6452):283-286

19. Manoury B, Tamuleviciute A, Tammaro P (2010) TMEM16A/ anoctamin 1 protein mediates calcium-activated chloride currents in pulmonary arterial smooth muscle cells. J Physiol 588:2305

20. Maricq AV, Korenbrot JI (1988) Calcium and calcium-dependent chloride currents generate action potentials in solitary cone photoreceptors. Neuron 1(6):503-515

21. Mizuta K, Tsutsumi S, Inoue H, Sakamoto Y, Miyatake K, Miyawaki K, Noji S, Kamata N, Itakura M (2007) Molecular characterization of GDD1/TMEM16E, the gene product responsible for autosomal dominant gnathodiaphyseal dysplasia. Biochem Biophys Res Commun 357(1):126-132

22. Namkung W, Yao Z, Finkbeiner WE, Verkman AS (2011) Smallmolecule activators of TMEM16A, a calcium-activated chloride channel, stimulate epithelial chloride secretion and intestinal contraction. FASEB J 25(11):4048-4062

23. Nilius B, Droogmans G (2001) Ion channels and their functional role in vascular endothelium. Physiol Rev 81(4):1415-1459

24. Nilius B, Droogmans G (2002) Calcium-activated chloride channels in vascular endothelial cells. In: Fuller CM (ed) Calcium-activated chloride channels, vol 53. Curren topics in membranes. Academic, San Diego, pp 327-344

25. Nilius B, Prenen J, Szucs G, Wei L, Tanzi F, Voets T, Droogmans G (1997) Calcium-activated chloride channels in bovine pulmonary artery endothelial cells. J Physiol 498(Pt 2):381-396

26. Nilius B, Prenen J, Voets T, Van den Bremt K, Eggermont J, Droogmans G (1997) Kinetic and pharmacological properties of the calcium-activated chloride-current in macrovascular endothelial cells. Cell Calcium 22(1):53-63

27. Ousingsawat J, Kongsuphol P, Schreiber R, Kunzelmann K (2011) CFTR and TMEM16A are separate but functionally related Clchannels. Cell Physiol Biochem: Int J Exp Cell Physiol Biochemi Pharmacol 28(4):715-724

28. Pieper U, Webb BM, Dong GQ, Schneidman-Duhovny D, Fan H, Kim SJ, Khuri N, Spill YG, Weinkam P, Hammel M, Tainer JA, Nilges M, Sali A (2014) ModBase, a database of annotated comparative protein structure models and associated resources. Nucleic Acids Res 42(Database issue):D336-346

29. Pifferi S, Dibattista M, Menini A (2009) TMEM16B induces chloride currents activated by calcium in mammalian cells. Pflugers Arch 458(6):1023-1038

30. Romanenko VG, Catalan MA, Brown DA, Putzier I, Hartzell HC, Marmorstein AD, Gonzalez-Begne M, Rock JR, Harfe BD, Melvin JE (2010) Tmem16A encodes the Ca2+-activated Cl- channel in mouse submandibular salivary gland acinar cells. J Biol Chem 285(17):12990-13001
31. Schroeder BC, Cheng T, Jan YN, Jan LY (2008) Expression cloning of TMEM16A as a calcium-activated chloride channel subunit. Cell 134(6):1019-1029

32. Scudieri P, Sondo E, Caci E, Ravazzolo R, Galietta LJ (2013) TMEM16A-TMEM16B chimeras to investigate the structurefunction relationship of calcium-activated chloride channels Biochem J 452(3):443

33. Shimizu T, Iehara T, Sato K, Fujii T, Sakai H, Okada Y (2013) TMEM16F is a component of a Ca2+-activated Cl- channel but not a volume-sensitive outwardly rectifying Cl- channel. Am J Physiol Cell Physiol 304(8):C748-759

34. Sreerama N, Woody RW (2004) Computation and analysis of protein circular dichroism spectra. Methods Enzymol 383:318-351

35. Stephan AB, Shum EY, Hirsh S, Cygnar KD, Reisert J, Zhao H (2009) ANO2 is the cilial calcium-activated chloride channel that may mediate olfactory amplification. Proc Natl Acad Sci U S A 106(28):11776-11781

36. Suzuki J, Umeda M, Sims PJ, Nagata S (2010) Calcium-dependent phospholipid scrambling by TMEM16F. Nature 468(7325):834-838

37. Tian Y, Schreiber R, Kunzelmann K (2012) Anoctamins are a family of Ca2+-activated Cl- channels. J Cell Sci 125(Pt 21):4991-4998

38. Tien J, Peters CJ, Wong XM, Cheng T, Jan YN, Jan LY, Yang H (2014) A comprehensive search for calcium binding sites critical for TMEM16A calcium-activated chloride channel activity. Elife: e02772

39. Tsunenari T, Nathans J, Yau KW (2006) Ca2+-activated Cl- current from human bestrophin-4 in excised membrane patches. J Gen Physiol 127(6):749-754

40. Tsutsumi S, Inoue H, Sakamoto Y, Mizuta K, Kamata N, Itakura M (2005) Molecular cloning and characterization of the murine gnathodiaphyseal dysplasia gene GDD1. Biochem Biophys Res Commun 331(4):1099-1106

41. Tsutsumi S, Kamata N, Vokes TJ, Maruoka Y, Nakakuki K, Enomoto S, Omura K, Amagasa T, Nagayama M, Saito-Ohara F, Inazawa J, Moritani M, Yamaoka T, Inoue H, Itakura M (2004) The novel gene encoding a putative transmembrane protein is mutated in gnathodiaphyseal dysplasia (GDD). Am J Hum Genet 74(6):12551261

42. Verkman AS, Galietta LJ (2009) Chloride channels as drug targets. Nat Rev Drug Discov 8(2):153-171

43. Xiao Q, Cui Y (2014) Acidic amino acids in the first intracellular loop contribute to voltage- and calcium-dependent gating of anoctamin1/TMEM16A. PLoS One 9(6):e99376

44. Xiao Q, Yu K, Perez-Cornejo P, Cui Y, Arreola J, Hartzell HC (2011) Voltage- and calcium-dependent gating of TMEM16A/Ano1 chloride channels are physically coupled by the first intracellular loop. Proc Natl Acad Sci U S A 108(21):8891-8896

45. Xiong LW, Kleerekoper QK, Wang X, Putkey JA (2010) Intra- and interdomain effects due to mutation of calcium-binding sites in calmodulin. J Biol Chem 285(11):8094-8103

46. Yang H, Kim A, David T, Palmer D, Jin T, Tien J, Huang F, Cheng T, Coughlin SR, Jan YN, Jan LY (2012) TMEM16F forms a Ca2+activated cation channel required for lipid scrambling in platelets during blood coagulation. Cell 151(1):111-122

47. Yang YD, Cho H, Koo JY, Tak MH, Cho Y, Shim WS, Park SP, Lee J, Lee B, Kim BM, Raouf R, Shin YK, Oh U (2008) TMEM16A confers receptor-activated calcium-dependent chloride conductance. Nature 455(7217):1210-1215

48. Yu K, Duran C, Qu Z, Cui YY, Hartzell HC (2012) Explaining calcium-dependent gating of anoctamin-1 chloride channels requires a revised topology. Circ Res 110(7):990-999

49. Yuan P, Leonetti MD, Pico AR, Hsiung Y, MacKinnon R (2010) Structure of the human BK channel $\mathrm{Ca} 2+$-activation apparatus at 3.0 A resolution. Science 329(5988):182-186

50. Zygmunt AC (1994) Intracellular calcium activates a chloride current in canine ventricular myocytes. Am J Physiol 267(5 Pt 2):H1984-1995 